\title{
Acute effects of caffeine on threat-selective attention: moderation by anxiety and EEG theta/beta ratio
}

\author{
Dana van Son ${ }^{1,2}$, Rik Schalbroeck ${ }^{1}$, Angelos Angelidis ${ }^{1,2}$, Nic van der Wee ${ }^{3}$, Willem van der \\ Does $^{1,2,3}$, Peter Putman ${ }^{1,2}$ \\ ${ }^{1}$ Institute of Psychology, Leiden University, Leiden, The Netherlands \\ ${ }^{2}$ Leiden Institute for Brain and Cognition, Leiden, The Netherlands \\ ${ }^{3}$ Leiden University Medical Center (LUMC), Leiden, The Netherlands
}

\begin{abstract}
Background: Spontaneous EEG theta/beta ratio (TBR) likely marks prefrontal cortical (PFC) executive control, and its regulation of attentional threat-bias. Caffeine at moderate doses may strengthen executive control through increased PFC catecholamine action, dependent on basal PFC function.
\end{abstract}

Goal: To test if caffeine affects threat-bias and if baseline frontal TBR moderates this effect.

Methods: Forty female participants were tested in a cross-over, double-blind study after placebo and $200 \mathrm{mg}$ caffeine. A pictorial emotional Stroop task was used to measure threat-bias.

Results: At baseline and after placebo, a direct effect of baseline TBR was observed on threat-bias, also interacting with trait-anxiety, for negative pictures only. Caffeine had opposite effects on threatbias for people with low and high TBR, cancelling out caffeine's main effect.

Conclusions: This further supports TBR as a marker of executive control and highlights the importance of taking baseline executive function into consideration when studying effects of caffeine on executive functions.

150 words

Keywords: EEG theta/beta ratio, attentional bias to threat, caffeine 


\section{Introduction}

Anxiety disorders are one of the most common mental health problems with point prevalence rates estimated around 7.3\% worldwide (Baxter, Scott, \& Whiteford, 2013). Individuals with an anxiety disorder excessively attend to threatening information and this may also be observed in individuals at risk (Mogg and \& Bradley, 2016; Ledoux; 1995). This tendency is usually referred to as an attentional bias (AB) towards threat.

A large number of studies have confirmed a positive relation between anxiety levels and $A B$ toward (mild) threat and it is thought that threat AB might maintain anxiety disorders (Mogg \& Bradley, 1998; 2016; Bar-Haim, Lamy, Pergamin, Bakermans-Kranenburg \& van IJzendoorn, 2007; Cisler \& Koster, 2010; van Bockstaele, Verschuere, Tibboel, De Houwer, Crombez \& Koster, 2014). $\mathrm{AB}$ is also thought to partially explain the well-documented association between anxiety and reduced cognitive performance through facilitating the processing of task-unrelated threatening information at the cost of task-directed attentional control and working memory capacity (Hembree, 1988; Putwain, 2009; Owens, Stevenson, Hadwin \& Norgate, 2012; Eysenck, Derakshan, Santos \& Calvo, 2007; Derakshan \& Eysenck, 2009; Cassady \& Johnson, 2002; Bishop, 2008). Bottom-up processing of salient information might cause selective and automatic attention to threat, while top-down cognitive control facilitates more goal-directed cognition and behavior (e.g., Eysenck et al., 2007; Hermans, Henckens, Joels \& Fernandez, 2014; Mogg \& Bradley, 2016). This is in line with findings of Derryberry and Reed (2002) who found that trait attentional control, as assessed with the attentional control scale (ACS; Derryberry \& Reed 2002) regulates automatic attention to threatening stimuli. Since their original study, several studies have reported that individual differences in attentional control (AC) are associated with the occurrence of threat-bias (often depending on levels of trait anxiety). In these studies, AC was measured either by self-report (e.g., Bishop, Jenkins \& Lawrence, 2007; Derryberry \& Reed, 2002; Putman, Arias-Garcia, Pantazi \& van Schie, 2012; Schoorl, Putman, van der Werff, \& van der Does, 2014; Taylor, Cross \& Amir, 2016) or with objectively assessed measures (Hou, Moss-Morris, Risdale, Lynch, Jeevaratnam, Bradley \& Mogg, 2014; ReinholdtDunne, Mogg \& Bradley, 2009; Angelidis, Hagenaars, van Son, van der Does \& Putman, 2018; van 
Son, Angelidis, Hagenaars, van der Does \& Putman, 2018).

Goal oriented, top-down attentional control is mediated by prefrontal-cortical networks (Derakshan \& Eysenck, 2009; Bishop, 2008; Gregoriou, Rossi, Ungerleider \& Desimone, 2014), whose function is dependent on adequate catecholamine action (Hermans et al., 2014; Arnsten, 2009a). Stress and anxiety trigger a variety of neurochemical changes (Joëls \&Baram, 2009), including increased influx of the catecholamines dopamine and nor-adrenaline into the prefrontal cortex (PFC). These processes are partly genetically determined and individually different (Kvetnansky, Sabban \& Palkovits, 2009). Both types of catecholamines influence PFC in a dosedependent, inverted U-shaped manner (Arnsten, 2009). While moderate levels are needed for good prefrontal executive control, dopaminergic and noradrenergic over-stimulation leads to decreased PFC function. In other words, increasing levels of catecholamines are associated with increasing performance until a tipping point is reached, after which further catecholamine stimulation will harm executive performance, including top-down attentional control (Arnsten, 2009a; Arnsten, 2011b; Arnsten \& Rubia, 2012; Hermans et al., 2014). This tipping point for the effects of stress-induced catecholamines (the apex of the inverted U-shape relation between catecholamines and cognitive performance) has been found to be dependent on catecholamine-driven basal prefrontal function, and is therefore different for every individual (Arnsten, 2009a; Arnsten 2009b; Cools \& D’Esposito, 2011). This implies that a well-dosed manipulation of catecholamine systems could increase attentional control over threat-bias, depending on individual differences in anxiety and baseline PFC function or catecholamine levels (Arnsten, 2006; Arnsten, 2011b).

A pharmacon that has repeatedly been linked to facilitated attentional and working memory functioning is caffeine (Lorist \& Tops, 2003). Caffeine works as an antagonist of adenosine receptors. Because adenosine inhibits nor-adrenaline and dopamine, caffeine indirectly stimulates dopamine and nor-adrenaline release, which in turn affect cognitive processes regulated by the PFC (Ribeiro \& Sebatião, 2010). Consequently, consuming caffeine may affect PFC processes such as executive control and working memory, which is in line with the existing literature on caffeine and cognitive performance (Klaassen, de Groot, Evers, Snel, Veerman, Ligtenberg \& Veltman, 2013; Haller, Rodriguez, Moser, Toma, Hofmeister, Sinanaj \& Lovblad, 2013; Greer, McLean \& Graham, 1998). 
The effects of caffeine consumption on PFC-regulated cognitive performance are dose-dependent and thereby seem to follow a similar inverted U-shape curve as described for the effects of stress and catecholamines on PFC-regulated performance (Arnsten, 2009a). In particular, in healthy humans, smaller doses (i.e., up to $200 \mathrm{mg}$ ) have positive effects on performance, while higher doses (e.g. above $400 \mathrm{mg}$ ) have no further benefit for cognitive functioning or even impair performance (Einöther \& Giesbrecht, 2013; Pasman, van Baak, Jeukendrup \& de Haan, 1995; Smillie \& Gökçen, 2010; Wood, Sage, Shuman \& Anagnostaras, 2014). The first aim of the present study was therefore to investigate whether caffeine administration affects cognitive performance depending on anxiety levels and basal PFC executive control.

A potential objective electrophysiological measure for PFC regulated attentional control can be derived from spontaneous (also known as “resting-state”) activity in electroencephalography (EEG). Previous studies reported that the ratio between power in the theta $(4-7 \mathrm{~Hz})$ and the beta (13-30 $\mathrm{Hz}$ ) frequency bands (theta/beta ratio; TBR) was negatively correlated to self-reported trait attentional control (ACS; Putman, van Peer, Maimari \& van der Werff, 2010; Putman, Verkuil, Arias-Garcia, Pantazi \& van Schie, 2014; Angelidis, van der Does, Schakel \& Putman, 2016) and positively correlated to stress-induced decline of state attentional control (Putman et al., 2014). Recent studies from our own lab showed that TBR moderated AB to stimuli of different threat-levels (Angelidis et al., 2018; van Son et al., 2018). Also, increased frontal TBR has been related to PFC-mediated attentional and inhibitory functions as seen in attention deficit/hyperactivity disorder (ADHD; for reviews and meta-analyses see Arns, Conners, \& Kraemer, 2013; Barry, Clarke, \& Johnstone, 2003). Frontal TBR is suggested to reflect inhibitory functional cortical-subcortical interactions (Knyazev, 2007; Schutter \& Knyazev, 2012) and to reflect voluntary top-down processes like attentional control carried out by the dorso-lateral PFC (Bishop, 2008; Gregoriou et al., 2014) over automatic bottom-up processes mediated by limbic areas such as the anterior cingulate cortex and the amygdala which facilitate attention to salient information (Hermans et al., 2014).

Interestingly, the administration of methylphenidate as treatment for ADHD improves cognitive functioning by enhancing dopamine and nor-adrenaline transmission in the PFC (Arnsten, 2006), and was also found to reduce theta and increase beta waves (thus normalized TBR; Clarke et 
al., 2007; Moreno-García, Delgado-Pardo \& Roldán-Blasco, 2015). Additionally, a positive relation was found between reduced TBR caused by methylphenidate administration and ADHD symptom reduction (Loo, Cho, Hale, McGough, McCracken \& Smalley, 2013). Again, when referring to the 'inverted U-shape’ relation of cognitive performance and catecholaminergic activity, it is expected that effects of methylphenidate are most favourable in individuals with low PFC activity (thus lower attentional control; Devilbiss \& Berridge, 2008). The findings that methylphenidate reduces frontal TBR, while ameliorating PFC-mediated cognitive difficulties in ADHD, in healthy individuals (Putman et al., 2014; Angelidis et al., 2016) and in individuals suffering from psychiatric or neurological disorders (Arns et al., 2013; Barry et al., 2003; Loo et al., 2013; Keune, Hansen, Weber, Zapf, Habich, Muenssinger, Wolf \& Oschmann, 2017) again support the relation between frontal TBR and executive (attentional) control.

Altogether, frontal TBR is suggested to be a reliable electrophysiological marker of executive and attentional control. This may in particular be the case during the processing of emotional information (Morillas-Romero, Tortella-Feliu, Bornas, \& Putman, 2015), making frontal TBR a promising tool to investigate cognitive-affect regulation. This includes the study of the effects of psychopharmacological manipulations on attentional control over salient emotional distracters, which likely depend on baseline PFC functioning. This was the second topic that we aimed to address in the present study.

To assess distraction by negative (threatening) task-irrelevant information on cognitive performance, we chose to use the Pictorial Emotional Stroop Task (PEST). The emotional Stroop task in its common form presents neutral and emotionally relevant stimuli in different colors. Participants have to indicate the color as fast as possible while ignoring the irrelevant (emotional) content of the stimuli. When the color-naming of emotional stimuli is slower relative to the color-naming of neutral stimuli, emotional interference is said to have occurred, either as a result of inability to inhibit the automatic attentional processing of the stimuli or because a bottom-up threat detection triggers the automatic inhibition of ongoing cognitive and behavioral activity, causing reduced task performance (Algom, Chajut \& Lev, 2004; Williams, Mathews \& McLeod, 1996; Mogg \& Bradley, 2016). Emotional interference by threatening stimuli is most easily demonstrated in people with elevated 
anxiety and for stimuli of great personal or acute relevance (Williams et al., 1996). In order to sensitively measure interference in a healthy sample, we opted to use a variant of the emotional Stroop task using highly arousing photographical stimuli of threatening and positive scenes. Although attentional avoidance of highly arousing threatening stimuli is also reported, mostly for tasks that measure visual-spatial attention (e.g., Cisler \& Koster, 2010; Eysenck et al., 2007) and as a function of trait anxiety and cognitive control levels (Mogg \& Bradley, 2016; Angelidis et al., 2018; van Son et al., 2018), we expected to find strong interference in baseline and placebo conditions which should enable to clearly test effects of our psychopharmacological manipulation on attentional control over threat-bias.

Taken together, the positive relation between caffeine and executive cognitive performance makes it interesting to investigate the effects of caffeine consumption on threat-bias. Since frontal TBR is considered to reflect basal functioning of PFC executive control (and hence possibly catecholamine function) and should therefore be related to individual differences of the catecholamine tipping point, we expected frontal TBR to moderate the effect of caffeine on threat-bias. Furthermore, trait anxiety was expected to further moderate these effects. We used a moderate dose of caffeine in a relatively caffeine-naïve sample (max daily consumption of $100 \mathrm{mg}$ ), to prevent influence of caffeine withdrawal effects (Juliano \& Griffiths, 2004). We hypothesized that:

I) Increased frontal TBR is related to interference in the PEST as measured on baseline or after placebo.

II) A moderate dose of caffeine, moderated by individual differences in frontal TBR should reduce interference as measured with the PEST.

III) Trait anxiety interacts with these relations between frontal TBR and interference and the effects of caffeine thereon.

IV) Caffeine mediates the relation (if present) between TBR and interference in the PEST.

These hypotheses are primarily aimed at the threatening stimuli, especially hypothesis III. However, for relations with frontal TBR and caffeine (hypotheses I and II), it is possible that also distraction by 
positive stimuli and effects of caffeine thereon are moderated by frontal TBR. Therefore, also a condition with positive stimuli was added to the PEST in order to assess valence-specificity. These hypotheses were tested as part of a larger study wherein also effects of caffeine on measures of nonemotional executive cognition were tested, including possibly mediating effects by caffeine-induced TBR changes. Those results are reported elsewhere (manuscript in preparation).

\section{Methods}

Participants

Forty female participants (between 18 and 25 years old) recruited at Leiden University took part in this study. The participants were preselected for consuming a maximum of $100 \mathrm{mg}$ caffeine per day (equivalent of about one cup of coffee). Caffeine consumption was assessed via self-report. Exclusion criteria were factors which could likely adversely affect participation or alter effects of caffeine on EEG or attention, including daily smoking, severe physical or psychological dysfunction, and/or the use of psychotropic medication. Participants were asked to abstain from caffeine and alcohol consumption for 12 hours before the start of lab sessions. Informed consent was obtained prior to testing, and participants received a monetary reimbursement for their participation. The study protocol was pre-registered (Clinicaltrials.gov: NCT02940808) and approved by the local medicalethical review board

Materials

\section{Questionnaires}

Participants completed the trait version of the State-Trait Anxiety Inventory (STAI-t; Spielberger, 1983; Van der Ploeg, Defares \& Spielberger, 1980) and the Attentional Control Scale (ACS; Derryberry \& Reed, 2002; Verwoerd, de Jong, \&Wessel, 2006). The STAI-t assesses trait anxiety (20 items, range 20-80; Cronbach's alpha in the current study $=0.85$ ), by indicating their agreement with items like 'I feel nervous and restless' and 'I have disturbing thoughts' on a four-point 
Likert scale. The ACS assesses self-reported attentional control in terms of attentional focus, attentional switching and the capacity to quickly generate new thoughts (20 items, range 20-80; Cronbach's alpha in present study $=0.86$ ), by indicating agreement with items like 'I can quickly switch from one task to another' and 'I have a hard time concentrating when I'm excited about something'.

\section{Caffeine}

Participants orally consumed either one capsule containing $200 \mathrm{mg}$ of caffeine or an undistinguishable placebo capsule containing a filler only. A capsule was administered during a second and third test session, while no capsule was administered during the first test session which served as a baseline condition (see below). Thus, there were three test sessions in total, all separated by approximately one week. The order of administration of the capsules during the second and third session was counterbalanced and randomized, and researchers and participants were blind to the contents of the capsules. Caffeine and placebo capsule preparation, labelling and blinding was done by the pharmacy of the Leiden University Medical Center (LUMC).

\section{Pictorial Emotional Stroop Task (PEST) stimuli}

For the Pictorial Emotional Stroop task (PEST), 72 pictures $^{1}$ (24 per test-day) were used from the International Affective Picture System (IAPS, Center for the Study of Emotion and Attention, 1999), a standardized set of emotion eliciting, colour pictures with normative ratings for valence and arousal. Of these pictures, per test-day, eight were categorized as positive (e.g. people enjoying sports), eight as negative (almost all depicting cues to immediate threat to bodily integrity, e.g. mutilated bodies, interpersonal attack and dangerous animals) and eight as neutral pictures (e.g., a towel). The pictures were subjectively matched on colour and composition. The pictures were selected according to the ratings for valence and arousal (scale 1-9; valence 1: very unpleasant to 9: very pleasant and arousal scales; 1: not arousing at all to 9: very arousing) provided by Lang et al (2005). The mean valence score over all test moments for positive stimuli was $M=7.22(S D=1.54)$, neutral 
$M=5.00(S D=1.16)$ and for negative stimuli $M=2.42(S D=1.54)$; the mean arousal scores were $M$

$=5.33(S D=2.21), M=2.70(S D=1.91)$ and $M=6.33(S D=2.21)$, respectively.

\section{NOTE 1 BELOW THIS PAGE}

\section{EEG recording and software}

Recordings for frontal theta and beta activity were obtained from the Fz, F3, and F4 10/20 positions using Ag/AgCl electrodes of the ActiveTwo BioSemi system (BioSemi, The Netherlands). Electrodes placed on the left and right mastoids were used for offline re-referencing of the scalp signals to the mastoid signals. The PEST and questionnaires were programmed and presented using EPrime 2.0 software (Psychology Software Tools, Pittsburgh, PA).

\section{Procedure}

\section{General Procedure}

Participants were tested on three separate days. Each of the three lab sessions was separated by approximately one week $(M=7.7$ days, $S D=2.5)$. On the first testing day (will be referred to as 'baseline results') participants completed questionnaires including demographics, ACS and STAI-t. In addition, baseline EEG was measured to provide a trait-like measure for TBR (see Angelidis et al., 2016 and Keune et al., 2017 for re-test reliability of TBR which ranged between $r=0.86$ and $r=0.93$ ). Baseline TBR as measured during this first session will be used for all analyses in this paper. Participants were then familiarized and practiced with tasks measuring different aspects of cognition (besides the PEST, these were a measure of attentional control for non-emotional processing and a working memory task for non-emotional processing; these outcome measures are used for different research questions that are reported elsewhere). Participants completed these tasks on the first day to reduce the occurrence of learning effects between drug-testing sessions and to provide an indication for baseline performance. Hypotheses for caffeine administration were tested by comparing the results for the cross-over drug-testing days 2 and 3.

During the second testing day, participants had to complete short questionnaires assessing their current alertness, fatigue, arousal and attentional control, Participants then received an eight- 
minute recording of spontaneous (resting-state) EEG and eye blink rate (EBR; reported elsewhere) in alternating one-minute blocks of eyes open/closed (reported elsewhere). Subsequently, participants ingested a capsule containing either caffeine (200 mg) or placebo (double-blind, randomized administration). As it takes some time for caffeine to affect CNS activity after oral administration (Nehlig, Daval, \& Debry, 1992), the participants did some passive recreation (e.g., read magazines) for 30 minutes. This was again followed by the same eight-minute recording of spontaneous (restingstate) EEG and EBR. Finally, participants completed the same cognitive tasks as they completed on the first day. On the third testing day the testing protocol of the second day was repeated, except that the other, remaining caffeine (200 mg) or placebo capsule was administered.

To examine whether blinding was successful, debriefing interviews were held at the end of the final lab session in which participants were asked to guess which capsule they had consumed in which session. Additionally, participants were asked to rate how certain they were that their guess was correct, on a scale of 1 (“Not certain at all”) to 10 ("Very certain”).

PEST

During the PEST, participants sat at a distance of $70 \mathrm{~cm}$ from the screen on which the stimuli were presented. The task consisted of 24 practice and 96 test trials. Every picture was presented in a random order with 32 positive, 32 negative and 32 neutral trials. Each trial started with an inter-trial interval (ITI) of $2000 \mathrm{~ms}$. The ITI was followed by a picture that was presented on a grey screen for $200 \mathrm{~ms}$ either $1.5 \mathrm{~cm}$ from the two edges of the left upper corner, right upper corner, left bottom corner, or right button corner of the screen. Pictures were presented with a height of $10.2 \mathrm{~cm}$ and width of $13.6 \mathrm{~cm}$ on a $30 \mathrm{~cm}$ x $50 \mathrm{~cm}$ screen. After the picture presentation, a coloured square of 1.3 cm by $1.3 \mathrm{~cm}$ was superimposed on the previously presented picture. The coloured squares were presented for 1800 ms (irrespective of response time) and were pseudo randomly chosen from three possible options (red, yellow, or blue) on each trial (for each picture, every colour appeared in a different location: centered top or bottom x centered left or right). The participants were asked to indicate as fast as possible without making too many mistakes the colour of the square with same coloured buttons using the index, middle or ring finger of their dominant hand using buttons of a 
response box (Psychology Software Tools, Pittsburgh, PA).

\section{Data Processing}

\section{PEST data pre-processing}

Incorrect responses were excluded from analyses. Color discrimination was measured in milliseconds and individual reaction times (RTs) that were shorter than $300 \mathrm{~ms}$ or longer than $1200 \mathrm{~ms}$ were defined as outliers and removed from the data. Secondly, individual RTs that deviated more than 2.5 standard deviations from the individual RT mean after this first filtering were also defined as outliers and were removed. This resulted in a total average percentage of $7.76 \%$ trials removed. Interference scores were calculated per condition separately for positive and negative trials. Interference scores were calculated for positive trials by distracting mean RTs of the neutral condition from mean RTs of the positive condition, and negative interference scores were calculated by distracting mean RTs of the neutral condition from mean RTs of the negative condition. Positive interference scores reflect longer RTs for trials with emotional pictures (or increased cognitive responding to emotional pictures) and negative scores reflect shorter RTs for trials with emotional pictures (or decreased processing of emotional pictures).

\section{EEG pre-processing}

Data processing was done using Brain Vision Analyzer V2.0.4 (Brain Products GmbH, Germany). Data was high-pass filtered at $0.1 \mathrm{~Hz}$, low-pass filtered at $100-\mathrm{Hz}$ and a $50-\mathrm{Hz}$ notch filter was applied. The data was automatically corrected for ocular artifacts (Gratton, Coles \& Donchin, 1983) in segments of 4 seconds. Fast Fourier transformation (Hamming window length 10\%) was applied to calculate power density for the beta (13-30 Hz) and theta (4-7 Hz) band. Our main interest was the power density average of the frontal electrodes and power density average of the F3, Fz and F4 positions as in Putman et al. (2010; 2014) and Angelidis et al. (2016), therefore these frontal averages were calculated for both the beta and theta band. Frontal TBR was calculated by dividing the frontal theta by frontal beta power density. A high frontal TBR reflects relatively more theta than beta 
power. Frontal TBR values were non-normally distributed and therefore log-normalized with a $\log 10$ transformation.

\section{Results}

Participants

Visual inspection before data analysis showed that EEG data of two participants were of bad quality and these participants were removed from all analyses. Remaining participants $(N=38)$ had a mean age of 21.90 years $(S D=2.05$, range: $18-25)$ mean STAI-t score was $34.6(S D=6.7$, range 23-53). The mean frontal TBR of the remaining participants that was measured during resting state on the first testing day (baseline results) was 1.25 ( $S D=0.63$, range 0.49-2.60 [non log-normalized]). Participants had an average caffeine consumption of approximately 53 milligram per day. Twenty-nine of the 38 participants (76\%) indicated to use either oral contraceptives or a hormonal intra-uterine device. All analyses were controlled for contraceptive use however no differences in significance were observed.

\section{PEST results}

The average number of errors out of 96 trials was $3.97(S D=5.25)$ in the baseline condition, 3.34 (SD $=2.39)$ in the caffeine condition and $3.71(S D=2.18)$ in the placebo condition. Mean RTs and SDs per trial-type per condition and interference scores of the PEST are presented in Table $\mathbf{1 .}$

\section{TABLE 1 ABOUT HERE}

\section{Baseline PEST interference scores}

We first analyzed the baseline interference scores using a repeated measures analysis of variance (ANOVA) with Valence (positive vs negative interference scores) as the as a within-subjects factor. A main effect of Valence was found, $F(1,37)=16.49, p<0.001, \eta p^{2}=0.31$, indicating larger interference for negative compared to positive stimuli. Follow-up $t$-tests showed that for this baseline data, both the interference score for positive stimuli $(t(1,37)=4.97, p<0.001)$ as well as negative 
stimuli $(t(1,37)=8.09, p<0.001)$ were significantly different from 0 .

Moderation analyses for the role of frontal TBR and trait anxiety at baseline

Next, we investigated whether baseline frontal TBR moderated positive versus negative interference scores, by adding TBR as covariate to the RM ANOVA. No significant main effect was found for frontal TBR, $F(1,36)=0.46, p=0.502, \eta p^{2}=0.013$, and there was no moderation effect for frontal TBR on Valence, $F(1,36)=0.55, p=0.465, \eta p^{2}=0.015$.

Furthermore, we investigated the role of trait anxiety on the TBR $\times$ Valence interaction, by adding STAI-t as a covariate to the model. No significant main effect of TBR, $F(1,34)=0.88, p=$ 0.356, $\eta p^{2}=0.025$, or TBR $\times$ STAI-t interaction, $F(1,34)=1.25, p=0.271, \eta p^{2}=0.036$ was found. However, a significant frontal TBR $\times$ STAI-t $\times$ Valence interaction was found, $F(1,34)=4.95, p=$ $0.033, \eta p^{2}=0.127$

To further test this three-way interaction; interference scores of negative and positive stimuli were tested separately in a univariate ANOVA, again adding frontal TBR and STAI-t as covariates to the model. No main effect of TBR was present for positive stimuli, $F(1,34)=0.32, p=0.574, \eta p^{2}=$ 0.009 , or negative stimuli, $F(1,34)=0.98, p=0.328, \eta p^{2}=0.028$. Also, no three-way interaction of TBR $\times$ STAI-t $\times$ valence (neutral versus positive) was found for the positive stimuli, $F(1,34)=0.08, p$ $=0.778, \eta p^{2}=0.002$, but a trend level three-way interaction effect was present for negative stimuli, $F(1,34)=3.98, p=0.054, \eta p^{2}=0.105$. Because the results indicate that the moderation of negativevalence by the frontal TBR $\times$ STAI-t interaction was restricted to negative interference, we conducted an additional simple slopes analysis for the dependent variable of interference in the negative condition (Aiken, West \& Reno, 1991) to illustrate this interaction, see Figure.1. We performed these follow-up analyses even though the interaction just failed to reach significance, in order to provide the necessary information for later comparison between baseline PEST performance and placebo PEST performance. These analyses revealed that the frontal TBR $\times$ STAI-t interaction was different for individuals with low STAI-t ( 1 SD below the mean; $\beta=-19.22, t(1,34)=-1.18, p=0.24$ ) mean STAI-t $(\beta=2.99, t(1,34)=0.25, p=0.80)$ and high STAI-t $(1$ SD above the mean; $\beta=25.19, t(1,34)=-1.55$, $p=0.13)$. As can be seen, the trend-level effect of TBR $\times$ STAI-t is such that for low STAI-t people, 
low TBR (1 SD below the mean) is associated with high interference for negative stimuli, but interference is lower for high TBR (1 SD above the mean). For people with high STAI-t, the influence of TBR is reversed with less interference for low compared to high TBR.

\section{FIGURE 1. ABOUT HERE}

Placebo versus Caffeine

All analyses including the placebo and caffeine conditions (Drug) were controlled for order effects, however results will be reported without order in the design as not to lose statistical power.

Placebo versus caffeine effects on EEG

To examine the effects of caffeine consumption on EEG, we conducted a 2 (Drug) x 2 (Time) rm ANOVA, and first examined separate effects on theta and beta bands. Compared to placebo consumption, caffeine consumption significantly decreased power in the theta band, $F(1,37)=20.526$, $p<0.001, \eta p 2=0.357$, and in the beta band, $F(1,37)=48.297, p<0.001, \eta p^{2}=0.566$. No effect was however found on TBR, $F(1,37)=0.130, p=0.721, \eta p^{2}=0.003$. As no effect of caffeine were found on TBR, we were not able to test its effect on the TBR- PEST interference relation (Hypothesis IV).

\section{Moderation analyses PEST scores Placebo versus Caffeine}

To investigate the effects of caffeine on PEST responding, interference scores were analyzed using a Drug-type (2; placebo vs caffeine) $\times$ Valence (2; positive vs negative interference scores) repeated measures ANOVA. No main effect was found for Drug-type, $F(1,37)=0.20, p=0.65, \eta p^{2}=$ 0.005. We again found a main effect of Valence, $F(1,37)=34.49, p<0.001, \eta p^{2}=0.48^{2}$, but no interaction effect was found between Drug-type and Valence, $F(1,37)=0.03, p=0.87, \eta p^{2}=0.001$. NOTE 2 BELOW THIS PAGE

\section{TABLE 1 ABOUT HERE}


Moderation analyses for the role of frontal TBR and trait anxiety, Placebo versus Caffeine

A Mahalonobis distance test revealed two significant bivariate outliers for the relationship between frontal TBR and PEST interference in the placebo and caffeine condition $\left(D^{2}(2,36)=10.01\right.$; $\left.p=0.007 ; D^{2}(2,36)=10.87 ; p=0.004\right)$. These cases were removed for all further analyses on PEST data.

To test the role of frontal TBR in this model, again a Drug-type $\times$ Valence $(2 \times 2)$ repeated measures ANOVA was performed with frontal TBR (baseline) as a covariate to the model. No main effect of TBR, $\left.F(1,34)=0.88, p=0.354, \eta p^{2}=0.025\right)$, or interaction effect was found for Drug-type $\times$ TBR, $\left.F(1,34)=0.80, p=0.376, \eta p^{2}=0.023\right)$. There was a significant frontal Drug-type $\times$ TBR $\times$ Valence interaction, $F(1,34)=7.95, p=0.008, \eta p^{2}=0.19^{2}$. To follow up on this interaction, post-hoc correlations were performed between TBR and contrast scores of interference between Drug-type condition (interference in caffeine condition minus interference in placebo condition) separately for negative and positive interference scores; frontal TBR was significantly related to higher negativeinterference scores in the caffeine compared to the placebo condition ( $r=0.37, p=0.029$ ), but there was no significant correlation for this contrast for positive interference scores $(r=-0.17, p=0.313$ ). This confirms hypothesis II for threatening stimuli only.

To see whether trait anxiety has an effect on this Drug-type $\times$ Valence $\times$ frontal TBR interaction, the Drug-type $\times$ Valence repeated measures ANOVA was performed with frontal TBR and STAI-t as covariates in the model. No main effect of TBR regardless of valence $F(1,32)=1.67, p=$ 0.206, $\eta p^{2}=0.049$, or interaction effect regardless of valence was found for TBR $\times$ STAI, $F(1,32)=$ 1.26, $p=0.270, \eta p^{2}=0.038$ ). However, a significant interaction was present for frontal TBR $\times$ Drugtype $\times$ STAI-t $\times$ Valence $F(1,32)=9.49, p=0.004, \eta p^{2}=0.23^{2}$, confirming hypothesis III.

In order to assess the nature of this frontal TBR $\times$ STAI-t $\times$ Drug-type $\times$ Valence interaction on interference scores, 2 (Drug-type) $\times 2$ (Valence; emotional vs neutral) repeated measures ANOVAs were conducted for positive and negative conditions separately. Frontal TBR and STAI-t were added as covariates. The interaction of frontal TBR $\times$ STAI-t $\times$ Drug-type $\times$ Valence (positive-neutral 
stimuli) was not found for the positive stimuli, $F(1,32)=0.94, p=0.340, \eta p^{2}=0.03$, but was present for negative stimuli, $F(1,32)=5.77, p=0.022, \eta p^{2}=0.15^{2}$.

To clarify this complex four-way interaction and its constituent three-way interactions, additional simple slope analyses with threat-interference as a dependent variable were conducted separately for the caffeine and the placebo condition. For the Placebo condition, there was no main effect for TBR, $F(1,32)=1.509, p=0.228, \eta p^{2}=0.042$. However, a TBR $\times$ STAI-t interaction was found, $F(1,32)=9.40, p=0.004, \eta p^{2}=0.253^{2}$. It was found that the effect of TBR on threatinterference is negative and stronger for low STAI-t (1 SD or more below the mean; $\beta=-47.19$, $\left.t(1,32)=-3.77, p=0.001^{2}\right)$ compared to mean STAI-t $\left(\beta=-20.40, t(1,32)=-2.23, p=0.033^{2}\right)$, whereas it is positive and not significant for high STAI-t $(1$ SD above the mean; $\beta=6.40, t(1,32)=$ $0.50, p=0.619)$ see Figure 2a. As can be seen, the results for placebo are comparable to the baseline results (interference scores are overall lower for high TBR now): for low STAI-t participants, low TBR is associated with high interference for negative stimuli, but interference is lower for high TBR. For people with high STAI-t there seems little effect of TBR.

For the Caffeine condition however, no TBR main effect on interference scores was present, and the TBR $\times$ STAI-t interaction was not significant, $F(1,32)=0.19, p=0.665$, with no effects of TBR for low STAI-t $(\beta=0.43, t(1,32)=0.03, p=0.97)$ mean STAI-t $(\beta=4.51, t(1,32)=0.46, p=$ $0.65)$ or high STAI-t $(\beta=8.59, t(1,32)=0.63, p=0.53)$ see Figure $2 b$. The influences of individual difference variables are absent with all participants showing moderate interference scores.

\section{FIGURE 2 ABOUT HERE}

\section{Correlational analyses}

TBR did not correlate significantly with ACS score (partial $r=0.277, p=0.107$ ) or STAI-t score (partial $r=0.119, p=0.495$ ) when controlling for one another, neither did ACS and STAI-t score $(r=-0.301, p=0.074)$.

\section{Drug condition awareness}


Of the 38 participants included in the analyses, 33 (86.8\%) correctly guessed on which day they consumed caffeine. A binomial test showed that this percentage was significantly above $50 \%$ chance level, $p<0.001$. Participants reported a mean certainty of making a correct guess of 7.27 on a 1-10 scale $(S D=1.57)$. Often reported reasons for guessing which capsule was consumed included feeling more awake or alert and noticing physiological changes (e.g., feeling more tense or dizzy) on days on which caffeine was thought to be consumed, in contrast to feeling sleepier or noticing no difference in functioning on days on which placebo was thought to be consumed.

\section{Discussion}

This study investigated whether frontal EEG TBR moderates the effect of caffeine on threat-bias. At baseline and placebo condition, we found a significant main effect of TBR on interference, only in low anxious participants by negative stimuli. Specifically, higher TBR related to lower interfering effect of negative (threatening) stimuli in the Pictorial Emotional Stroop Task (PEST) in low anxious participants. Caffeine administration had opposite effects on threat-interference for people with low and high TBR (high and low PFC functioning), effectively cancelling out individual differences and a main effect for caffeine.

Our first hypothesis that TBR would be related to interference in the PEST was not confirmed as results were only present for low anxious individuals. Still, in low anxious individuals, our data indicate that the relation of TBR with interference was valence-specific; the effect was only present in arousing-threatening images, but not in arousing positive images. The role of TBR (as basal PFC functioning) has not yet been investigated between threatening and positive images, making the current results noteworthy, however, only for low anxious populations. Some studies looked only at negative arousal. It was for instance reported that TBR predicted reductions in self-reported attentional control after a socially threatening stress-manipulation (Putman et al., 2014). Also, higher TBR was related to less effective spontaneous down-regulation of the negative affect evoked by arousing negative stimuli (Tortella-Feliu, Morillas-Romero, Balle, Llabres, Bornas \& Putman, 2014). Another study (Putman et al., 2010) did include positive and negative stimuli and reported that TBR was related to a contrasting effect on RTs from fearful and happy faces in an emotional go-no go task, but 
contrary to the current study, this study did not compare these arousing conditions with a condition with neutral stimuli and therefore does not allows any firm conclusions for the specific processing of negative and positive stimuli. The current study directly tested and showed that the relation is specific for negative information, in low anxious participants. This finding implies that, dependent on trait anxiety, TBR possibly reflects the interplay between an executive attention-network and a salience network that is more active in states of negative arousal (Hermans et al., 2014; Kohn, Hermans \& Fernández, 2017).

Data for the baseline and placebo conditions showed that TBR was negatively related to interference from threatening pictures, again only in low anxious participants. When comparing our baseline and placebo results, the relation between TBR and interference effects seem to deviate looking at the direction of the mean slopes in negative stimuli. However, in both baseline and placebo condition, the relation directs to negative for low anxious and positive for highly anxious individuals. This interaction pattern turned out to be significant for low anxious individuals in the placebo condition and trend-level significant in the baseline data and. Also, follow up analyses only showed a significant relation in the placebo condition in negative stimuli. Despite this difference, some are of the opinion that when using simple slope analyses, the overall interaction is more important than effects per low or high values (Aiken, West \& Reno, 1991). It is therefore likely that both the baseline as placebo TBR - interference relation can be treated as equivalent.

It has previously been reported for other variants of the Emotional Stroop Task (EST), that lower cognitive control over automatic processing of threat information resulted in higher interference for threatening words (Jha, Krompinger \& Baine, 2007; Putman et al., 2012, for a review see BarHaim et al., 2007). TBR (negatively related to attentional control; see Lansbergen, van DongenBoomsma, Buitelaar, \& Slaats-Willemse. 2011; Zhang, Roodenrys, Li, Barry, Clarke, Wu, et al., 2017; Keune et al., 2017; Putman et al., 2010, Putman et al., 2014; Angelidis et al., 2016) was therefore expected to correlate positively with interference in the PEST. Thus only in low anxious individuals, our results demonstrated a negative relation between TBR and interference for threat, with individuals with higher TBR showing less interference or even negative interference scores on the PEST. Although studies using an EST have often found an interference effect of threatening words (e.g. 
Amir, Elias, Klumpp \& Przeworski, 2003; Putman et al., 2012; Gorlin \& Teachman, 2015) other EST studies have reported response facilitation (faster color naming responses to threatening than neutral stimuli) which is usually interpreted as reflecting attentional avoidance of the threatening content of the stimuli (e.g. Dandenau \& Baldwin, 2004; Egloff \& Hock, 2001; Edelstein \& Gillath, 2008; Putman, Hermans \& van Honk, 2004). Similar attentional avoidance has often been reported for spatial attention tasks for emotional information (for overviews see Cisler \& Koster, 2010; Mogg \& Bradley, 2016), where the avoidant response is evident from slower responses to trials where threatening stimuli cue the location of a subsequent target location (e.g. Amir, Foa, \& Coles, 1998; Koster, De Raedt, Goeleven, Franck \& Crombez, 2005; Mogg, Bradley, Miles, \& Dixon, 2004; Schoorl et al., 2014; Wald et al., 2011).

Such attentional avoidance in spatial tasks seems to occur mostly for very highly threatening (pictorial) stimuli and/or stimuli that are of a phobic nature to anxious participants (see Mogg \& Bradley, 2016). Many of the stimuli that we used were also highly threatening pictures cueing direct and acute threat to well-being (e.g. mutilated bodies and attacking animals) which seem more likely to evoke attentional avoidance in anxious people (anxiety is negatively related to attentional control). The model by Mogg and Bradley (1998; 2016) predicts that anxious hypervigilance is more likely to be evoked by mild threatening pictures whereas low levels of anxiety and high levels of cognitive control should be related to adaptive vigilance toward survival-relevant highly threatening pictures. Indeed, our healthy sample as a whole demonstrated strong average interference score of 50 and $34 \mathrm{~ms}$ for baseline and placebo conditions to our threat pictures. The finding that for low anxious individuals, higher TBR was associated with reduced interference is as predicted from this theoretical framework and is in line with recent findings from two studies in our lab, similarly reporting more vigilance/less avoidance for such highly threatening pictures in people with low TBR (Angelidis et al., 2018; van Son et al., 2018). The spatial dot-probe task and emotional cueing task that previously demonstrated anxious attentional avoidance of graphic threat seem greatly influenced by response facilitation or a slow-down in responding when attention needs to be disengaged from a threatening cueing stimulus preceding the target response (Koster, et al., 2005; Koster, Crombez, Verschuere \& De Houwer, 2006; Mogg et al., 2004) and also overall response slowing has been observed for trials with threatening cues 
(Koster et al., 2005). These response-slowing in disengagement processes might not be fundamentally different from slowed response in our PEST. Especially because influences on disengagement of spatial attention from salient visual information cannot be excluded for the PEST since it is not unlikely that the colour targets often appear in another location of the background pictures than the parts that especially draw or hold attention.

One of the purposes of this study was to see whether trait anxiety would moderate the effect of frontal TBR on threat interference. This turned out to be the case; the effect of TBR seemed only to be present in individuals with lower trait anxiety. Although predictions for the effect of trait anxiety on PFC regulated processes can be made based on the existing literature (e.g. Mogg \& Bradly, 1998; 2016; Derryberry \& Reed (2002), studies investigating the specific relation between trait anxiety and executive control have had rather inconsistent results. Derryberry \& Reed (2002) reported that attentional control is essentially effective for threat selective attention in highly anxious individuals, and Schoorl et al., (2014) also reported a stronger effect of AC on mildly threatening stimuli in higher anxious individuals suffering from post-raumatic stress disorder (PTSD). More recent data (Angelidis et al., 2018) however, suggest that the effect of TBR as PFC-regulated executive control was mainly present in low trait anxious individuals (for highly threatening stimuli). These results are in line with the current study. However, the Dot Probe task that was used in Angelidis et al., (2018) had separate categories of mild and high threatening stimuli, which was not the case in the PEST as presently used, making our results difficult to compare. We therefore refrain from drawing any strong conclusion about the exact role of trait anxiety. For now, we speculate that threat-related stimuli usually involve automated uncontrolled responses (e.g. Ledoux, 1995), likely especially in high anxious individuals (Bar-Haim et al., 2007; Cisler \& Koster, 2010) and therefore individual differences in attentional control might have only limited influence in high anxious people. Nevertheless, we conclude that it remains unclear what the role of trait anxiety is in the effects of caffeine administration on control over threat-selective attention. Future studies should revisit this issue in designs allowing better control over the influence of anxiety, for instance by preselecting participants on levels of trait anxiety or manipulating state anxiety, as well as target the effect of stimuli of different threat-levels.

No correlation was found between TBR, ACS score or ACS and STAI-t which was peculiar 
taking the repeatedly found negative correlation of TBR or STAI-t and ACS and into account (e.g. Putman et al., 2010; Putman et al., 2014; Angelidis et al., 2016; Derryberry \& Reed, 2002). Two other studies however likewise failed to replicate the TBR - ACS correlation (Tortella-Feliu et al., 2014; Angelidis et al., 2018) suggesting that whether these concepts truely relate remains questionable. Yet, the current participant sample was pre-selected on having a very low caffeine usage, possibly making it difficult to compare this sample to previously used groups of healthy subjects. The occasional absence of the TBR - ACS relation might however indicate that TBR mainly seems to represent attentional control in emotional contexts such as during threat processing or threat interference (Tortella-Feliu et al., 2014; Morillas-Romero et al., 2015; Putman et al., 2010; Putman et al., 2014; Angelidis et al., 2018) and doesn’t represent core attentional processes per se.

Caffeine did not seem to affect TBR, but theta and beta separately significantly reduced after caffeine administration. Previous literature reported effects of caffeine on separate EEG theta and beta activity (e.g., Kaplan et al., 1997; Landolt et al., 2004; Keane \& James, 2008), but mixed results have been found depending on the sample studied (e.g., caffeine non-consumers versus regular consumers), design employed (e.g., acute effects versus long-term consumption), and dose of caffeine administered, making it difficult to verify whether caffeine actually causes a decrease in the theta or the beta band. As beta has commonly been found to be related to motor inhibition (e.g. Engel \& Fries, 2010), one possible explanation of the beta decrease found in the current study might be because participants had to sit still during the eight-minute baseline measurement even though the caffeine manipulation might have caused motoric stimulation (Fisone, Borgkvist \& Usiello, 2004; for a review see Ferré, 2008). Still, more research, possibly controlling for motoric inhibitions, is required for resolving the exact effects of caffeine on the theta and beta bands.

Importantly though, despite the absence of an effect of caffeine on TBR, TBR of low anxious individuals showed a significant direct relation with responding in the PEST and this was clearly influenced by caffeine administration. Participants with low trait anxiety and higher TBR who showed less interference/more facilitation in baseline and placebo conditions showed more interference/less facilitation in the caffeine condition. Contrariwise, participants with lower TBR who showed more threat interference/less facilitation in baseline and placebo conditions showed less interference after 
caffeine administration. This pattern of responding is in line with the predicted moderation of caffeine's effects by baseline TBR. Given the evidence that lower TBR is related to better prefrontal cortical control (Angelidis et al., 2016; Barry et al., 2003; Keune et al., 2017), and better prefrontal cortical control over the automatic attentional processing of salient threatening stimuli (Putman et al., 2010; Angelidis et al., 2018; van Son et al., 2018) and assuming that such basal prefrontal attentional control is regulated by prefrontal catecholamine levels (Arnsten, 2006; Hermans et al., 2014), the established model of inverted U-shape relations between prefrontal catecholamine activity and cognitive attentional control (Arnsten, 2006; Arnsten, 2009a; Cools and D’Esposito, 2011) would predict just that. Furthermore, having a strong test-retest correlation (Angelidis et al., 2016; Keune et al., 2017), when being measured during resting state, TBR possibly reflects more structural or tonal aspects of brain activity compared to the phasic processes that one would expect after such temporal mild psychopharmacological effect like caffeine administration. Though studies investigating the effects on TBR after ADHD medication suggest otherwise (e.g. see Clarke et al., 2007) and found TBR to change, therefore this issue remains unclear and needs further investigation.

Several studies have already provided evidence for the inverted U-shape effect of caffeine and its relation to PFC moderation of catecholamines (for a review see Dobson and Hunt, 2013). This nonlinear pattern may depend on dopamine activity, as the optimal dose of caffeine and its increase of baseline PFC-related dopamine activity is different for every individual (Arnsten, 2009a). Larger doses of caffeine resulted in poor PFC mediated cognitive functioning (Wood et al., 2014; Kaplan, Greenblatt, Ehrenberg, Goddard, Cotreau \& Shader et al., 1997). The same was reported for cognitive performance and caffeine-doses; performance of individuals on short-term memory and attentional tasks depended on caffeine-dose in an inverted U-shape function (Anderson, 1990; Anderson \& Revelle, 1983; Gilliland, 1980, Revelle, Humphreys, Simon \& Gilliland, 1980). Studies in rats support this notion; rats with lower baseline working memory performance showed a stronger increase in performance when measured PFC dopamine efflux was higher compared to rats with higher initial baseline working memory performance (Phillips, Ahn \& Floresco, 2004; Murphy, Arnsten, GoldmanRakic \& Roth, 1996; for a review see Cools \& D‘Esposito, 2011). Similarly, Aston-Jones \& Cohen (2005) found nor-adrenaline levels in the locus coeruleus of monkeys to modulate performance on 
attentional tasks in the same inverted-U-shaped relation. In the current study, caffeine affected participants with better baseline attentional control (as evident from baseline TBR and baseline/placebo PEST performance) in such a way that their performance after caffeine resembled more the baseline/placebo performance of participants with less attentional control. Performance of people with less attentional control resembled more the baseline/placebo performance of people with better attentional control after caffeine administration. Therefore, the results of our study support the notion that effects of caffeine on executive cognitive performance, like catecholamine manipulations, depend on (likely catecholamine-mediated) baseline prefrontal executive performance and indirectly support the notion that effects of caffeine on executive function likely follow an inverted U-shape dose-response relation (Arnsten, 2009a; Einöther \& Giesbrecht, 2013; Pasman et al., 1995; Wood et al., 2014). Whether effects of caffeine are most strongly present in prefrontal/cortical areas however remains uncertain as caffeine affected adenosine receptors were actually found to be highly expressed in subcortical/limbic areas (Sebastião \& Ribeiro, 2009).

To sum up, we aimed to study effects of caffeine on attentional control over threat-bias and how baseline frontal TBR interacts with these effects. Results were as expected; caffeine administration influenced interference in the PEST, which was moderated by baseline TBR, used as a marker of basal PFC executive control. No effect of caffeine was however found on TBR. Our findings likely confirm previous suggestions that TBR reflects executive control in healthy individuals (Angelidis et al., 2016; Putman et al., 2010, 2014; Angelidis et al., 2018; van Son et al., 2018). Previous reports describe that caffeine up-regulates PFC activity, but has different effects on attentional performance depending on baseline catecholamine activity in the PFC (Arnsten, 2009a; Arnsten 2009b; Cools \& D’Esposito, 2011). Including measures that reflect basal PFC regulated executive control might thus improve studies of effects of caffeine on prefrontal cognitive processing, making TBR a possibly useful tool in psychopharmacological studies, e.g. when investigating the role of catecholamines in attentional performance. Moreover PFC-mediated attentional control was found to have a key function in the processing of emotional information such as selective attention to threat or cognitive appraisal (Ochsner, Silvers, \& Buhle, 2012), which is usually impaired in different types of psychopathology (Etkin \& Wager, 2007; Joormann \& Gotlib, 2010), therewith using TBR can be 
beneficial when studying for example threat selective attention and emotion regulation.

Potential limitations of this study include that the threat-level of the pictures used in the PEST was not manipulated. As discussed above, whether participants direct attention toward or away from a stimulus, depends on whether stimuli are highly or mildly threatening (Angelidis et al., 2018; van Son et al., 2018; Mogg \& Bradley, 2016; Bar-Haim et al., 2007). Follow-up studies should therefore explicitly target the effect of stimuli of different threat-levels. Also, this study did control for contraceptive use, however no accurate data was present of the participant's menstrual cycle phase, and was therefore not controlled. Future studies should obtain such data to minimize possible hormonal influences on psychophysiological measurements. Furthermore, participants guessed accurately whether caffeine or placebo was administered and were therefore not blind to the manipulation - at least at the end of the second drug/placebo testing session though not necessarily during PEST performance. Theoretically, results might thus have been affected by an expectancy bias due to the participant's knowledge of whether caffeine was given or not. Given that interference as measured by the PEST is relatively implicit, and the finding that the effect of caffeine was solely present when including a physiological measure, we assume it to be unlikely that the non-blindness of our study has influenced the final results. However, this finding demonstrates a larger issue in studies of caffeine administration and many other psychopharmacological experiments in human subjects. Such studies rarely measured or reported whether participants were aware of the drug they had received in a manner similar to ours (see Ahluwalia \& Herrick, 2015). Our inclusion of debriefing the participants about condition awareness should thus foremost be seen as a methodological strength and future studies should surely implement this methodological control.

In conclusion, this study supports the notion of frontal TBR as an electrophysiological marker for executive control, this time only in low anxious individuals, and is possibly a useful approximation of individual differences in baseline prefrontal catecholamine function that could be used when, for example, investigating catecholamine manipulation. It also confirms that caffeine can affect attentional control over automatic threat-attention depending on baseline individual differences. 
ACKNOWLEDGEMENTS: This study is supported by a grant from the Netherlands Organization for Scientific Research (NWO; \#452-12-003) to Dr. P. Putman. NWO was not involved in any part of the current study. All authors were involved in the study design and approved the final manuscript.

\section{References}

Ahluwalia, N., and Herrick, K. (2015). Caffeine intake from food and beverage sources and trends among children and adolescents in the United States: review of national quantitative studies from 1999 to 2011. Advances in Nutrition: An International Review Journal, 6(1), 102-111.

Aiken, L. S., West, S. G., \& Reno, R. R. (1991). Multiple regression: Testing and interpreting interactions. Sage.

Algom, D., Chajut, E., and Lev, S. (2004). A rational look at the emotional stroop phenomenon: a generic slowdown, not a stroop effect. Journal of experimental psychology: General, 133(3), 323.

Amir, N., Foa, E. B., and Coles, M. E. (1998). Automatic activation and strategic avoidance of threatrelevant information in social phobia. Journal of Abnormal Psychology, 107(2), 285-290.

Amir, N., Elias, J., Klumpp, H., and Przeworski, A. (2003). Attentional bias to threat in social phobia: facilitated processing of threat or difficulty disengaging attention from threat?. Behaviour research and therapy, 41(11), 1325-1335.

Anderson, K. J. (1990). Arousal and the inverted-u hypothesis: A critique of Neiss's" Reconceptualizing arousal.".

Anderson, K. J., and Revelle, W. (1983). The interactive effects of caffeine, impulsivity and task demands on a visual search task. Personality and Individual Differences, 4(2), 127-134.

Angelidis, A., Hagenaars, M., van Son, D., van der Does, W., Putman, P., Do not look away! Association of frontal EEG theta/beta ratio as a marker for cognitive control with (mal)adaptive attention to stimuli of different threat intensity. Biological Psychology, In press

Angelidis, A., van der Does, W., Schakel, L., and Putman, P. (2016). Frontal EEG theta/beta ratio as an electrophysiological marker for attentional control and its test-retest reliability. Biol Psychol, 121(Pt A), 49-52.

Arnsten, A. F. (2009a). Stress signalling pathways that impair prefrontal cortex structure and function. Nature reviews. Neuroscience, 10(6), 410.

Arnsten, A. F. (2009b). Toward a new understanding of attention-deficit hyperactivity disorder pathophysiology. CNS drugs, 23(1), 33-41.

Arnsten, A.F.T (2011b). Catecholamine influences on dorsolateral prefrontal cortical networks. Biological Psychiatry, 69, 89-99.

Arnsten, A. F. T. (2006). Stimulants: Therapeutic actions in ADHD Neuropsychopharmacology (Vol. 
31, pp. 2376-2383).

Arnsten, A. F., and Rubia, K. (2012). Neurobiological circuits regulating attention, cognitive control, motivation, and emotion: disruptions in neurodevelopmental psychiatric disorders. Journal of the American Academy of Child and Adolescent Psychiatry, 51(4), 356-367.

Arns, M., Conners, C. K., and Kraemer, H. C. (2013). A decade of EEG Theta/Beta Ratio Research in ADHD: a meta-analysis. J Atten Disord, 17(5), 374-383.

Aston-Jones, G., and Cohen, J. D. (2005). An integrative theory of locus coeruleus-norepinephrine function: adaptive gain and optimal performance. Annu. Rev. Neurosci., 28, 403-450.

Bar-Haim, Y., Lamy, D., Pergamin, L., Bakermans-Kranenburg, M. J., and van IJzendoorn, I. M. H. (2007). Threat-related attentional bias in anxious and nonanxious individuals: a meta-analytic study. Psychol Bull, 133(1), 1-24. doi:10.1037/0033-2909.133.1.1

Barry, R. J., Clarke, A. R., and Johnstone, S. J. (2003). A review of electrophysiology in attentiondeficit/hyperactivity disorder: I. Qualitative and quantitative electroencephalography. Clin Neurophysiol, 114(2), 171-183.

Baxter, A. J., Scott, K. M., Vos, T., and Whiteford, H. A. (2013). Global prevalence of anxiety disorders: a systematic review and meta-regression. Psychological medicine, 43(5), 897-910.

Bishop, S. J. (2008). Neural mechanisms underlying selective attention to threat. Ann N Y Acad Sci, 1129, 141-152.

Bishop, S. J., Jenkins, R., and Lawrence, A. D. (2007). Neural processing of fearful faces: effects of anxiety are gated by perceptual capacity limitations. Cereb Cortex, 17(7), 1595-1603.

Cassady, J. C., and Johnson, R. E. (2002). Cognitive test anxiety and academic performance. Contemporary educational psychology, 27(2), 270-295.

Center for the study of Emotion and Attention, National Institute of Mental Health. (1999). The International Affective Picture System. Gainesville, FL: University of Florida

Cisler, J. M., and Koster, E. H. (2010). Mechanisms of attentional biases towards threat in anxiety disorders: An integrative review. Clin Psychol Rev, 30(2), 203-216. doi:10.1016/j.cpr.2009.11.003

Clarke, A. R., Barry, R. J., McCarthy, R., Selikowitz, M., and Johnstone, S. J. (2007). Effects of stimulant medications on the EEG of girls with Attention-Deficit/Hyperactivity Disorder. Clin Neurophysiol, 118(12), 2700-2708.

Cools, R., and D'Esposito, M. (2011). Inverted-U-shaped dopamine actions on human working memory and cognitive control. Biological psychiatry, 69(12), e113-e125.

Dandeneau, S. D., and Baldwin, M. W. (2004). The inhibition of socially rejecting information among people with high versus low self-esteem: The role of attentional bias and the effects of bias reduction training. Journal of Social and Clinical Psychology, 23(4), 584-603.

Derakshan, N., and Eysenck, M. W. (2009). Anxiety, Processing Efficiency, and Cognitive Performance New Developments from Attentional Control Theory. European Psychologist, 14(2), 168-176.

Derryberry, D., and Reed, M. A. (2002). Anxiety-related attentional biases and their regulation by attentional control. Journal of Abnormal Psychology, 111(2), 225-236. doi:10.1037//0021- 
Devilbiss, D. M., and Berridge, C. W. (2008). Cognition-enhancing doses of methylphenidate preferentially increase prefrontal cortex neuronal responsiveness. Biological psychiatry, 64(7), 626635.

Dobson, N. R., and Hunt, C. E. (2013). Pharmacology review: caffeine use in neonates: indications, pharmacokinetics, clinical effects, outcomes. NeoReviews, 14(11), e540-e550.

Edelstein, R. S., and Gillath, O. (2008). Avoiding interference: Adult attachment and emotional processing biases. Personality and Social Psychology Bulletin, 34(2), 171-181.

Egloff, B., and Hock. M. (2001). Interactive effects of state anxiety and trait anxiety on emotional Stroop interference. Personality and Individual Differences, 31, 875-882.

Einöther, S. J., and Giesbrecht, T. (2013). Caffeine as an attention enhancer: reviewing existing assumptions. Psychopharmacology, 225(2), 251-274.

Etkin, A., and Wager, T. D. (2007). Functional neuroimaging of anxiety: a meta-analysis of emotional processing in PTSD, social anxiety disorder, and specific phobia. American Journal of Psychiatry, 164(10), 1476-1488.

Engel, A. K., \& Fries, P. (2010). Beta-band oscillations—signalling the status quo? Current opinion in neurobiology, 20(2), 156-165.

Eysenck, M. W., Derakshan, N., Santos, R., and Calvo, M. G. (2007). Anxiety and cognitive performance: attentional control theory. Emotion, 7(2), 336-353.

Gilliland, K. (1980). The interactive effect of introversion-extraversion with caffeine induced arousal on verbal performance. Journal of Research in Personality, 14(4), 482-492.

Ferré, S. (2008). An update on the mechanisms of the psychostimulant effects of caffeine. Journal of neurochemistry, 105(4), 1067-1079.

Fisone, G., Borgkvist, A., \& Usiello, A. (2004). Caffeine as a psychomotor stimulant: mechanism of action. Cellular and Molecular Life Sciences CMLS, 61(7-8), 857-872.

Gorlin, E. I., and Teachman, B. A. (2015). Inhibitory control as a moderator of threat-related interference biases in social anxiety. Cognition and Emotion, 29(4), 723-735.

Gratton, G., Coles, M. G., and Donchin, E. (1983). A new method for off-line removal of ocular artifact. Electroencephalography and clinical neurophysiology, 55(4), 468-484.

Gregoriou, G. G., Rossi, A. F., Ungerleider, L. G., and Desimone, R. (2014). Lesions of prefrontal cortex reduce attentional modulation of neuronal responses and synchrony in V4. Nat Neurosci, 17(7), 1003-1011.

Greer, F., McLean, C., and Graham, T. E. (1998). Caffeine, performance, and metabolism during repeated Wingate exercise tests. Journal of applied physiology, 85(4), 1502-1508.

Haller, S., Rodriguez, C., Moser, D., Toma, S., Hofmeister, J., Sinanaj, I., ... and Lovblad, K. O. (2013). Acute caffeine administration impact on working memory-related brain activation and functional connectivity in the elderly: a BOLD and perfusion MRI study. Neuroscience, 250, 364-371.

Hembree, R. (1988). Correlates, causes, effects, and treatment of test anxiety. Review of educational research, 58(1), 47-77. 
Hermans, E. J., Henckens, M. J., Joels, M., and Fernandez, G. (2014). Dynamic adaptation of largescale brain networks in response to acute stressors. Trends Neurosci, 37(6), 304-314.

Hou, R., Moss-Morris, R., Risdale, A., Lynch, J., Jeevaratnam, P., Bradley, B. P., and Mogg, K. (2014). Attention processes in chronic fatigue syndrome: attentional bias for health-related threat and the role of attentional control. Behav Res Ther, 52, 9-16.

Joëls, M., and Baram, T. Z. (2009). The neuro-symphony of stress. Nature reviews. Neuroscience, 10(6), 459.

Jha, A. P., Krompinger, J., and Baime, M. J. (2007). Mindfulness training modifies subsystems of attention. Cognitive, Affective, and Behavioral Neuroscience, 7(2), 109-119.

Joormann, J., and Gotlib, I. H. (2010). Emotion regulation in depression: relation to cognitive inhibition. Cognition and Emotion, 24(2), 281-298.

Juliano, L. M., and Griffiths, R. R. (2004). A critical review of caffeine withdrawal: empirical validation of symptoms and signs, incidence, severity, and associated features. Psychopharmacology, 176(1), 1-29.

Kaplan, G. B., Greenblatt, D. J., Ehrenberg, B. L., Goddard, J. E., Cotreau, M. M., Harmatz, J. S., and Shader, R. I. (1997). Dose-dependent pharmacokinetics and psychomotor effects of caffeine in humans. The Journal of Clinical Pharmacology, 37(8), 693-703.

Keane, M. A., \& James, J. E. (2008). Effects of dietary caffeine on EEG, performance and mood when rested and sleep restricted. Human Psychopharmacology: Clinical and Experimental, 23(8), 669-680.

Keune, P. M. , Hansen, A., Weber, E., Zapf, F., Habich, J., Muenssinger, J., Wolf, S., Schonenberg, M., Oschmann, P. (2017). Exploring neurophysiologic monitoring parameters and cognitive functioning in multiple sclerosis (MS): resting-state brain oscillatory activity and attention performance. Clinical neurophysiology

Klaassen, E. B., de Groot, R. H., Evers, E. A., Snel, J., Veerman, E. C., Ligtenberg, A. J., ... and Veltman, D. J. (2013). The effect of caffeine on working memory load-related brain activation in middle-aged males. Neuropharmacology, 64, 160-167.

Koster, E. H., Verschuere, B., Crombez, G., and Van Damme, S. (2005). Time-course of attention for threatening pictures in high and low trait anxiety. Behav Res Ther, 43(8), 1087-1098.

Kohn, N., Hermans, E. J., and Fernández, G. (2017). Cognitive benefit and cost of acute stress is differentially modulated by individual brain state. Social cognitive and affective neuroscience, nsx043.

Koster, E. H., De Raedt, R., Goeleven, E., Franck, E., and Crombez, G. (2005). Mood-congruent attentional bias in dysphoria: maintained attention to and impaired disengagement from negative information. Emotion, 5(4), 446.

Koster, E. H. W., Crombez, G., Verschuere, B., and De Houwer, J. (2006). Attention to threat in anxiety-prone individuals: Mechanisms underlying attentional bias. Cognitive Therapy and Research, 30(5), 635-643.

Knyazev, G. G. (2007). Motivation, emotion, and their inhibitory control mirrored in brain oscillations. Neuroscience and Biobehavioral Reviews, 31(3), 377-395.

Kvetnansky, R., Sabban, E. L., and Palkovits, M. (2009). Catecholaminergic systems in stress: structural and molecular genetic approaches. Physiological reviews, 89(2), 535-606. 
Landolt, H. P., Rétey, J. V., Tönz, K., Gottselig, J. M., Khatami, R., Buckelmüller, I., \& Achermann, P. (2004). Caffeine attenuates waking and sleep electroencephalographic markers of sleep homeostasis in humans. Neuropsychopharmacology, 29(10), 1933.

Lang, P. J. (2005). International affective picture system (IAPS): Affective ratings of pictures and instruction manual. Technical report.

Lansbergen, M. M., van Dongen-Boomsma, M., Buitelaar, J. K., and Slaats-Willemse, D. (2011). ADHD and EEG-neurofeedback: a double-blind randomized placebo-controlled feasibility study. Journal of neural transmission, 118(2), 275-284.

Ledoux, J. E. (1995). EMOTION - CLUES FROM THE BRAIN. Annual Review of Psychology, 46, 209-235.

Loo, S. K., Cho, A., Hale, T. S., McGough, J., McCracken, J., and Smalley, S. L. (2013).

Characterization of the theta to beta ratio in ADHD: identifying potential sources of heterogeneity. Journal of attention disorders, 17(5), 384-392.

Lorist, M. M., and Tops, M. (2003). Caffeine, fatigue, and cognition. Brain and cognition, 53(1), 8294.

Mogg, K., Bradley, B., Miles, F., and Dixon, R. (2004). BRIEF REPORT Time course of attentional bias for threat scenes: Testing the vigilance-avoidance hypothesis. Cognition and Emotion, 18(5), 689700.

Mogg, K., and Bradley, B. P. (1998). A cognitive-motivational analysis of anxiety. Behaviour Research and Therapy, 36(9), 809-848.

Mogg, K., and Bradley, B. P. (2016). Anxiety and attention to threat: Cognitive mechanisms and treatment with attention bias modification. Behaviour Research and Therapy, 87, 76-108.

Moreno-García, I., Delgado-Pardo, G., and Roldán-Blasco, C. (2015). Attention and response control in ADHD. Evaluation through integrated visual and auditory continuous performance test. The Spanish journal of psychology, 18.

Morillas-Romero, A., Tortella-Feliu, M., Bornas, X., and Putman, P. (2015). Spontaneous EEG theta/beta ratio and delta-beta coupling in relation to attentional network functioning and self-reported attentional control. Cogn Affect Behav Neurosci, 15(3), 598-606.

Murphy, B. L., Arnsten, A. F., Goldman-Rakic, P. S., and Roth, R. H. (1996). Increased dopamine turnover in the prefrontal cortex impairs spatial working memory performance in rats and monkeys. Proceedings of the National Academy of Sciences, 93(3), 1325-1329.

Nehlig, A., Daval, J. L., and Debry, G. (1992). Caffeine and the central nervous system: mechanisms of action, biochemical, metabolic and psychostimulant effects. Brain Research Reviews, 17(2), 139170.

Ochsner, K. N., Silvers, J. A., and Buhle, J. T. (2012). Functional imaging studies of emotion regulation: a synthetic review and evolving model of the cognitive control of emotion. Annals of the New York Academy of Sciences, 1251(1). 
Owens, M., Stevenson, J., Hadwin, J. A., and Norgate, R. (2012). Anxiety and depression in academic performance: An exploration of the mediating factors of worry and working memory. School Psychology International, 33(4), 433-449.

Pasman, W. J., van Baak, M. A., Jeukendrup, A. E., and de Haan, A. (1995). The effect of different dosages of caffeine on endurance performance time. International journal of sports medicine, 16(04), 225-230.

Phillips, A. G., Ahn, S., and Floresco, S. B. (2004). Magnitude of dopamine release in medial prefrontal cortex predicts accuracy of memory on a delayed response task. Journal of Neuroscience, 24(2), 547-553.

Putman, P., Hermans, E., and van Honk, J. (2004). Emotional stroop performance for masked angry faces: it's BAS, not BIS. Emotion, 4(3), 305.

Putman, P., van Peer, J., Maimari, I., and van der Werff, S. (2010). EEG theta/beta ratio in relation to fear-modulated response-inhibition, attentional control, and affective traits. Biol Psychol, 83(2), 73-78.

Putman, P., Arias-Garcia, E., Pantazi, I., and van Schie, C. (2012). Emotional Stroop interference for threatening words is related to reduced EEG delta-beta coupling and low attentional control. International Journal of Psychophysiology, 84(2), 194-200.

Putman, P., Verkuil, B., Arias-Garcia, E., Pantazi, I., and van Schie, C. (2014). EEG theta/beta ratio as a potential biomarker for attentional control and resilience against deleterious effects of stress on attention. Cognitive Affective and Behavioral Neuroscience, 14(2), 782-791.

Putwain, D. W. (2009). Assessment and examination stress in Key Stage 4. British Educational Research Journal, 35(3), 391-411.

Reinholdt-Dunne, M. L., Mogg, K., and Bradley, B. P. (2009). Effects of anxiety and attention control on processing pictorial and linguistic emotional information. Behaviour Research and Therapy, 47(5), 410-417.

Revelle, W., Humphreys, M. S., Simon, L., and Gilliland, K. (1980). The interactive effect of personality, time of day, and caffeine: A test of the arousal model. Journal of Experimental Psychology: General, 109(1), 1.

Ribeiro, J. A., and Sebastião, A. M. (2010). Caffeine and adenosine. Journal of Alzheimer's Disease, 20(S1), 3-15.

Schoorl, M., Putman, P., van der Werff, S., and van der Does, A. J. (2014). Attentional bias and attentional control in Posttraumatic Stress Disorder. J Anxiety Disord, 28(2), 203-210.

Schutter, D. J. L. G., and Van Honk, J. (2005). Electrophysiological ratio markers for the balance between reward and punishment. Cognitive Brain Research, 24(3), 685-690.

Schutter, D. J., and Knyazev, G. G. (2012). Cross-frequency coupling of brain oscillations in studying motivation and emotion. Motiv Emot, 36(1), 46-54.

Smillie, L. D., and Gökçen, E. (2010). Caffeine enhances working memory for extraverts. Biological psychology, 85(3), 496-498.

Spielberger, C. D. (1983). Manual for the State-Trait Anxiety Inventory (STAI form Y). Palo Alto: Consulting Psychologists Press. 
Taylor, C. T., Cross, K., and Amir, N. (2016). Attentional control moderates the relationship between social anxiety symptoms and attentional disengagement from threatening information. J Behav Ther Exp Psychiatry, 50, 68-76.

Tortella-Feliu, M., Morillas-Romero, A., Balle, M., Llabres, J., Bornas, X., and Putman, P. (2014). Spontaneous EEG activity and spontaneous emotion regulation. Int J Psychophysiol, 94(3), 365-372.

van Bockstaele, B., Verschuere, B., Tibboel, H., De Houwer, J., Crombez, G., and Koster, E. H. (2014). A review of current evidence for the causal impact of attentional bias on fear and anxiety. Psychol Bull, 140(3), 682-721.

van der Ploeg, H. M., Defares, P. B., and Spielberger, C. D. (1980). ZBV: Handleiding bij de zelfbeoordelings vragenlijst: Een Nederlandstalige bewerking van Spielberger State-Trait Anxiety Inventory STAI-Y. Amsterdam: Harcourt.

van Son, D., Angelidis, A., Hagenaars, M.A., van der Does, W., Putman, P. The role of individual differences in EEG theta/beta ratio, attentional control and trait anxiety in attentional bias to varying levels of threat. Manuscript submitted.

Wald, I., Shechner, T., Bitton, S., Holoshitz, Y., Charney, D. S., Muller, D., . . Bar-Haim, Y. (2011). Attention bias away from threat during life threatening danger predicts PTSD symptoms at one-year follow-up. Depress Anxiety, 28(5), 406-411.

Williams, J. M. G., Mathews, A., and MacLeod, C. (1996). The emotional Stroop task and psychopathology. Psychological bulletin, 120(1), 3.

Wood, S., Sage, J. R., Shuman, T., and Anagnostaras, S. G. (2014). Psychostimulants and cognition: a continuum of behavioral and cognitive activation. Pharmacological reviews, 66(1), 193-221.

Zhang, D. W., Roodenrys, S., Li, H., Barry, R. J., Clarke, A. R., Wu, Z., ... and Wang, Y. (2017). Atypical interference control in children with $\mathrm{AD} / \mathrm{HD}$ with elevated theta/beta ratio. Biological Psychology, 128, 82-88.

Table 1. Mean RTs and interference scores (standard deviations between parentheses) in milliseconds for the Pictorial Emotional Stroop task in the conditions 'baseline results', 'placebo' and 'caffeine' $(N=38)$.

\begin{tabular}{ccccc}
\hline & Condition & Neutral & Positive & Negative \\
\hline RT & Baseline & $586(82)$ & $609(89)$ & $636(97)$ \\
& Placebo & $557(78)$ & $564(81)$ & $591(93)$ \\
\multirow{3}{*}{ Interference } & Caffeine & $544(61)$ & $559(67)$ & $582(72)$ \\
& Baseline & & $22(32)$ & $50(38)$ \\
& Placebo & & $7(27)$ & $34(31)$ \\
& Caffeine & & $14(20)$ & $37(28)$
\end{tabular}


Note: $R T=$ reaction time. All interference scores, for baseline, placebo and caffeine conditions, were different from 0 with $p<0.001$. All interference scores for negative pictures were significantly larger than for positive pictures with $p<0.001$. Test-retest correlations of positive interference scores in the placebo condition with those in the caffeine condition were $r=0.318, p=0.058$ and correlations of negative interference scores in placebo condition with those in the caffeine condition were $r=0.353, p=0.035$. The interference scores in caffeine or placebo condition did not correlate significantly with those in baseline condition.

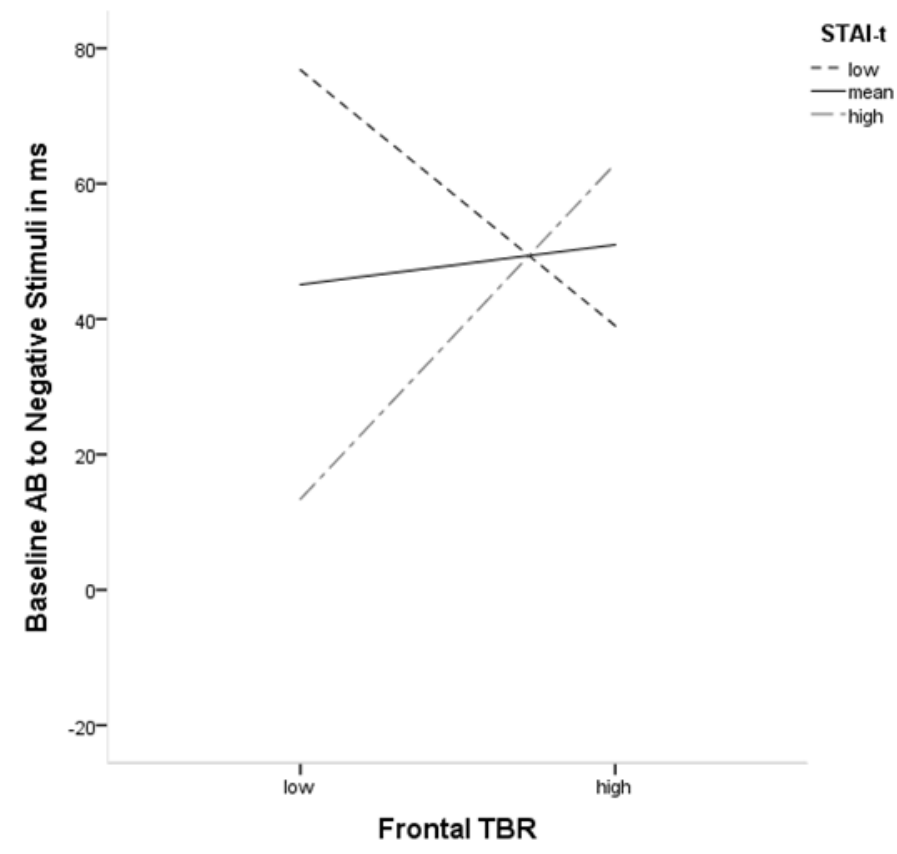

Figure 1. Simple slopes for the moderation of trait anxiety on the effect of Ln-normalized frontal EEG on negative interference $(A B=$ attentional bias $)$ in the PEST baseline results frontal $T B R=L n$ normalized theta/beta ratio. 

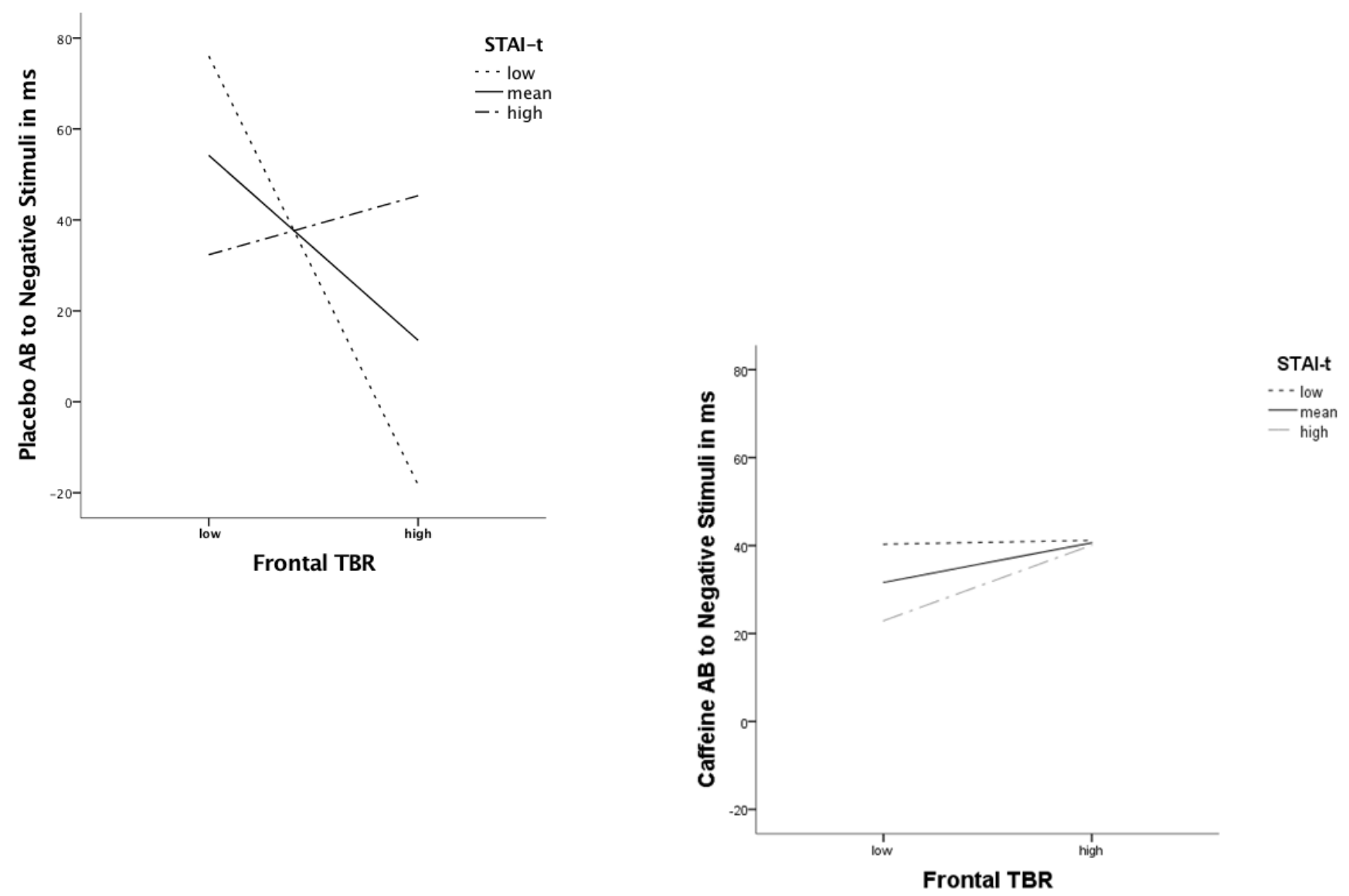

Figure 2ab. Simple slopes for the moderation of STAI-t on the effect of Ln-normalized frontal EEG on negative interference in the EST after consumption of placebo (a:left) or caffeine (b:right). Frontal $T B R=$ Ln-normalized frontal theta/beta ratio. In the placebo condition, increased frontal TBR was associated with stronger negative interference; an effect which was only significant for individuals with lower trait anxiety. No effects were found however in the caffeine condition.

\section{Notes}

${ }^{1}$ Used picture numbers in the PEST: Negative: $1120,1220,2981,3053,3120,3230,6315,6560,1070,1205,2900,3110,3261,6260,6540$, 3000, 3064, 1114, 1300, 2800, 3051, 3060, 6313, 6570; Positive: 1340, 2058, 8120, 8186, 8200, 8205, 8540, 8350, 1710, 2070, 7325, 8040, 
8192, 8370, 8460, 8490, 8470, 1750, 2040, 8161, 8300, 8400, 8497, 8620; Neutral: 5731, 7000, 7002, 7035, 7041, 7056, 7060, 7491, 5130, 7006, 7040, 7050, 7052, 7059, 7170, 7490, 5740, 7009, 7025, 7090, 7175, 7500, 7710, 7950.

${ }^{2}$ This interaction remained significant when controlling for order effects. 